\title{
HUBUNGAN POLA MAKAN DENGAN TERJADINYA OBESITAS ANAK USIA \\ SEKOLAH DI SDN KUTOREJO 1 KECAMATAN KERTOSONO \\ KABUPATAN NGANJUK
}

\author{
Hudha Endityawan', Rahayu Budi Utami ${ }^{2}$, Agus Khoirul Fuadi ${ }^{3}$ \\ ${ }^{123}$ Dosen STIKes Satria Bhakti Nganjuk \\ Email : hudha.enddy18@gmail.com
}

\begin{abstract}
Introduction: Irregular eating patterns such as excessive portions that are not controlled and become a habit in children that cause BB stastus in children will become more or obesity. The purpose of this study was to determine the relationship of diet with the occurrence of obesity of school age children in SDN Kutorejo 1 District Kertosono Nganjuk. Methods: This research uses associative design research (case control). This research was conducted on May 03, 2018 at SDN Kutorejo 1 District Kertosono Nganjuk. The population was all children in SDN Kutorejo 1 District Kertosono Nganjuk. A sample of 209 respondents were in accordance with inclusion criteria and exclusion criteria. The sampling technique was proportional stratified random sampling. Independent variables are diet and dependent variable of obesity of school age children. data collection using questionnaires. Statistical test using Coefficient Contingency with significance $\alpha=0,05$. Results: The research results obtained almost half of the 75 respondents $(35.9 \%)$ have a good diet and most of 152 respondents $(72.7 \%)$ are not obese. There were a relationship between diet and obesity where obtained $\rho$ value $=0,000$ because $\rho$ value $\leq \alpha(\alpha=0,05)$ then Ha accepted and Ho rejected. Conclusion: Poor eating patterns are very influential on the occurrence of obesity, where if school-age children get a diet that is not balanced or consume excess calories than consuming calories in a balanced manner will be at risk of obesity in school-age children
\end{abstract}

Keywords: Diet, Obesity, School-Age Children.

\section{PENDAHULUAN}

Obesitas merupakan kondisi kesehatan kronis, yang ditandai oleh terdapatnya penimbunan lemak yang berlebihan dari pada yang di perlukan untuk fungsi tubuh yang normal (Soetjiningsih, 2013). Pada masa pertumbuhan anak usia 6-12 tahun memiliki berat badan ideal sekitar $20 \mathrm{~kg}$ $39,5 \mathrm{~kg}$ (Soetjiningsih, 2013) Hasil penelitian tahun 2013 menunjukkan secara nasional masalah obesitas pada anak usia 6-12 tahun sangat tinnggi (Rikesdas, 2013). Obesitas atau kegemukan dari segi kesehatan merupakan salah satu penyakit salah gizi, sebagaimana akibat konsumsi makanan yang jauh melebihi kebutuhannya (Soetjiningsih, 2013). Hasil analisis data memperlihatkan terdapat hubungan antara pola makan dengan obesitas pada anak usia sekolah, menurut penelitian yusaac dkk (2007) menunjukkan bahwa subjek penalitian yang mengalami obesitas memiliki pola makan yang tidak seimbang yaitu pola konsumsi lemak dengan frekuensi sering yang proporsinya lebih 
besar dibandingkan dengan yang tidak obesitas.

Dalam sepuluh tahun terakhir, obesitas menjadi masalah global (WHO, 2015). Berdasarkan hasil pengamatan peneliti pada hari Selasa tanggal 14 November 2017 di SDN Kutorejo 1 Kecamatan Kertosono Kabupaten Nganjuk, dari 20 anak terdapat 12 anak (60\%) mengalami berat badan berlebih tidak sesuai dengan tinggi badannya dan 8 anak (40\%) BB tidak berlebih ,dari 12 anak yang memiliki BB berlebih semuanya (100\%) mereka lebih senang mengkonsumsi makanan berupa jajanan siap saji seperti sosis goreng, batagor, cilok, cireng dan sempol.

Bila melihat angka kejadian obesitas maka obesitas pada anak sampai kini masih merupakan masalah, satu dari 10 (sepuluh) anak di dunia mengalami obesitas dan peningkatan obesitas pada anak dan remaja saat ini sejajar dengan orang dewasa (WHO, 2013). Hasil riset kesehatan (RIKESDAS) tahun 2013 menunjukkan prevalensi kegemukan dan obesitas di indonesia pada anak sekolah (5-12 tahun) masih tinggi yaitu 18,8\%, terdiri dari gemuk 10,8\% dan sangat gemuk (obesitas) 8,0\%. Prevalensi gizi lebih (overweight) pada anak usia sekolah (6-12) di Provinsi Jawa Timur juga meningkat yaitu $12 \%$ pada 2010 dan tahun 2013 sebesar 12,4\% (kemenkes,
2010). Menurut DINKES Kabupaten Nganjuk tahun 2016 obesitas anak usia 612 tahun di Kabupaten Nganjuk 7,2\% dari 16.165 anak usia (6-12) yaitu 1.163 anak yang mengalami obesitas dan Kecamatan yang terbanyak mengalami obesitas anak (6-12) di Kecamatan Kertosono sebesar 23,4\% yaitu 273 anak, dari Kecamatan Kertosono anak (6-12) yang mengalami obesitas terbanyak yaitu di SDN Kutorejo 1 Kerosono sejumlah 40 anak berdasarkan studi awal, sehingga peneliti menentukan tempat di SDN Kutorejo 1 Kerosono.

Obesitas terjadi karena pola makan yang kurang baik, meningkatnya ketersediaan makanan di pasaran sehingga kecenderungan seseorang untuk makan akan meningkat. Masyarakat bisa memilih makanannya sendiri sehingga lebih mudah mengalami kelebihan asupan makanan dan kelebihan berat badan pun susah untuk di hindari (Freitag, 2010). Pola makan tidak teratur seperti porsi yang berlebihan yang tidak terkontrol dan menjadi suatu kebiasaan pada anak sehingga menyebabkan status gizi $\mathrm{BB}$ pada anak akan menjadi lebih atau over weight (Sulistyoningsih, 2011).. Bila kelebihan ini terjadi dalam jangka waktu lama, dan tidak diimbangi dengan aktivitas yang cukup untuk membakar kelebihan energi, lambat laun kelebihan energi tersebut akan diubah menjadi lemak dan ditimbun didalam sel lemak 
dibawah kulit. Akibatnya anak tersebut akan menjadi gemuk. Dampaknya apabila seorang anak menderita obesitas akan mendatangkan banyak masalah di kemudian hari seperti hiperlipidemia, hipertensi, resistensi insulin, arterosklerosis, dan penyakit jantung koroner (Soetjiningsih, 2013). Dan berdasarkan studi pendahuluan peneliti dari 20 anak terdapat 12 anak mengalami berat badan berlebih, dari 12 anak yang memiliki BB berlebih semuanya lebih senang duduk-duduk atau tidak melakukan aktivitas berlebihan dan dari pada ikut bermain dengan temannya saat istirahat, Dengan demikian pola makan perlu diperhatikan sebagai faktor yang menyebabkan obesitas.

Obesitas yang terjadi karena pola makan yang salah maka pola makan anak harus bener-bener di perhatikan, orang tua anak harus ada upaya agar anak tidak mengkonsumsi makan secara berlebihan ,upaya orang tua agar anak makan secara teratus baik frekuensi, jenis makanan maupun jumlah makanan. Hubungan pola makan dengan terjadinya obesitas anak usia sekolah di SDN Kutorejo 1 Kecamatan Kertosono Kabupaten Nganjuk.

\section{METODE}

Penelitian ini menggunakan jenis penelitian asosiatif (case control), dilakukan pada tanggal 03 Mei 2018 berlokasi di SDN Kutorejo 1 Kecamatan Kertosono Kabupaten Nganjuk. Populasi penelitian ini adalah Semua Anak Usia Sekolah di SDN Kutorejo 1 Kecamatan Kertosono Kabupaten Nganjuk sebanyak 439 orang. Teknik sampling Proportional Stratified Random Sampling sampel Anak Usia Sekolah di SDN Kutorejo 1 Kecamatan Kertosono Kabupaten Nganjuk sebanyak 209 orang. Variabel Pola Makan dan Terjadinya Obesitas Anak Usia sekolah. Pengumpulan data menggunakan kuesioner pola makan dengan indikator jenis makanan, frekuensi konsumsi makanan dan jumlah makanan untuk skor 0 : salah, 1 : benar kategori Baik : 76-100\%, Cukup : 56-75\%, Kurang : < 56\% (Nursalam,2016), timbangan digital (seca digital) dan microtois kategori Obesitas : 40 ke atas Tidak Obesitas : 18,4-39,9 (WHO, 2006). Uji statistik menggunakan Uji Coefisien Contingency dengan SPSS versi 16 pada $\alpha=$ 0,05 . 


\section{HASIL PENELITIAN}

Hubungan Pola Makan Dengan Terjadinya Obesitas Anak Usia Sekolah Di SDN Kutorejo 1 Kecamatan Kertosono Kabupatan Nganjuk

Tabel 1 Tabulasi Silang pola makan dengan terjadinya obesitas anak usia sekolah di di SDN Kutorejo 1 Kecamatan Kertosono Kabupaten Nganjuk pada tanggal 03 Mei 2018

\begin{tabular}{|c|c|c|c|c|c|c|}
\hline \multirow{3}{*}{ Pola Makan } & \multicolumn{4}{|c|}{ Obesitas } & \multirow{2}{*}{\multicolumn{2}{|c|}{ Jumlah }} \\
\hline & \multicolumn{2}{|c|}{ Obesitas } & \multicolumn{2}{|c|}{ Tidak Obesitas } & & \\
\hline & $\mathrm{F}$ & $\%$ & $\mathrm{~F}$ & $\%$ & $\mathrm{~F}$ & $\%$ \\
\hline Baik & 0 & 0 & 75 & 35,9 & 75 & 35,9 \\
\hline Cukup & 0 & 0 & 73 & 34,9 & 73 & 34,9 \\
\hline Kurang & 57 & 27,3 & 4 & 1,9 & 61 & 29,2 \\
\hline Jumlah & 57 & 27,3 & 152 & 72,7 & 209 & 100 \\
\hline \multicolumn{7}{|c|}{ Uji Coefisien Contingency $\rho$ value $=0,000$ pada $\alpha=0,05$} \\
\hline
\end{tabular}

Berdasarkan Tabel 1 menunjukkan bahwa dari 209 responden, hampir setengahnya yaitu 75 responden $(35,9 \%)$ memiliki pola makan baik dan tidak mengalami obesitas.

\section{Berdasarkan uji Coefisien} Contingency didapatkan $\rho$ value $=0,000$ pada $\alpha=0,05$. Karena $\rho$ value $\leq \alpha=0,05$ maka Ha diterima sehingga ada hubungan pola makan dengan terjadinya obesitas anak usia sekolah di Kecamatan Kertosono Kabupaten Nganjuk dengan tingkat hubungan kuat.

\section{PEMBAHASAN}

1. Pola makan anak usia sekolah di SDN 1 Kutorejo Kecamatan Kertosono Kabupaten Nganjuk.
Berdasarkan hasil penelitian dari 209 responden, hampir setengahnya yaitu 75 responden $(35,9 \%)$ pola makannya baik. Dari 75 responden yang pola makannya baikhampir setengahnya yaitu 38 responden $(42,2 \%)$ pendidikan terakhir ibu adalah perguruan tinggi, hampir setengahnya yaitu 41 responden $(46,6 \%)$ pendidikan terakhir bapak adalah perguruan tinggi, hampir setengahnya 42 responden (29\%) pekerjaan ibu adalah ibu rumah tangga, hampir setengahnya yaitu 39 responden (30,2\%) pekerjaan bapak yaitu lainya (wiraswasta). Hal ini dibuktikan dengan $\rho$ value pendidikan terakhir $\mathrm{ibu}=0,000, \rho$ value pendidikan terakhir bapak $=0,000, \rho$ value pekerjaan $\mathrm{ibu}=0,000, \rho$ value pekerjaan bapak $=$ 0,000 , sehingga pola makan di pengaruhi 
oleh pendidikan terakhir ibu, pendidikan terakhir bapak, pekerjaan ibu, pekerjaan bapak secara signifikan.

Menurut Roviana Nurda (2017) dalam Jurnalnya tentang Hubungan Pola Makan Dan Persepsi Orang Tua Dengan Kejadian Obesitas Pada Anak Usia 8-13 Tahun Di SD Budi Mulia Dua Seturan Yogyakarta, Tingkat pendapatan orangtua berkaitan dengan pendidikan dan status pekerjaan. Pendidikan dan status pekerjaan orangtua di SD BMD Seturan Yogyakarta tergolong berpendidikan tinggi dan memiliki pekerjaan seperti dosen, dokter, peneliti, TNI, polisi, wiraswasta, karyawan swasta sehingga pendapatan yang di dapatkan semakin tinggi. Tingkat pendapatan orangtua berkaitan dengan kemampuan mencukupi kebutuhan, pemilihan jenis dan jumlah makanan, serta berpengaruh terhadap gaya hidup keluarga yang juga akan berdampak pada anak. pola makan dan persepsi orang tua dengan kejadian obesitas pada anak usia 8 - 13 tahun di sd budi mulia dua seturan yogyakarta

Kecenderungan pola makan kurang baik terjadi pada anak yang memiliki orangtua dengan tingkat pendidikan tinggi dan status pekerjaan orang tua seperti PNS, TNI, Polisi, dan wiraswasta sehingga tingkat pendapatan orang tua yang didapat semakin tinggi. Tingkat pendapatan orangtua berkaitan dengan kemampuan mencukupi kebutuhan dan uang jajan anak sehingga berpengaruh terhadap gaya hidup keluarga yang juga akan berdampak pada anak. Orangtua dan keluarga memiliki peranan yang sangat penting dalam pemilihan makanan dan minuman yang sehat untuk dikonsumsi anak, serta harus mendukung untuk memulai gaya hidup sehat agar anak pola makannya teratur.

\section{Terjadinya obesitas anak usia sekolah di SDN 1 Kutorejo} Kecamatan Kertosono Kabupaten Nganjuk.

Berdasarkan hasil penelitian dari 209 responden sebagian besar yaitu 152 responden $(72,7 \%)$ tidak mengalami Obesitas. Dari 152 responden sebagian besar yaitu 98 responden anak (74,8\%) jumlah saudaranya adalah 1, hampir seluruhnya yaitu 80 responden $(88,9 \%)$ pendidikan terakhir ibunya adalah perguruan tinggi, hampir seluruhnya 78 responden $(88,6 \%)$ pendidikan terakhir bapak adalah perguruan tinggi. Hal ini di buktikan dengan $\rho$ value Jumlah saudara $=$ 0,000 , $\rho$ value Pendidikan terakhir ibu $=$ $0,000, \rho$ value pendidikan terakhir bapak $=$ 0,000, Sehingga obesitas dipengaruhi oleh jumlah saudara, pendidikan terakhir ibu dan pendidikan terkahir bapak secara signifikan. 
Menurut Irwan Hariyanto,(2012) dalam Jurnalnya tentang Faktor-Faktor Yang Berhubungan Dengan Obesitas Pada Anak Usia Sekolah Dasar Di Jawa Tengah, menunjukkan anak-anak yang memiliki 3 saudara kandung atau kurang lebih cenderung menjadi kelebihan berat badan dibandingkan dengan anak-anak yang memiliki lebih dari 3 bersaudara. Saudara kandung yang lebih sedikit dan lebih sedikit orang dirumah memiliki hubungan yang signifikan dengan kelebihan berat badan dan kegemukan.

Menurut Budiyati ,(2011) dalam Jurnalnya tentang Analisis Faktor Penyebab Obesitas Pada Anak Usia Sekolah Di SD Islam AL-AZHAR 14 Kota Semarang, menunjukkan dengan pendidikan yang lebih tinggi, orang tua mempunyai sikap, pengetahuan, dan perilaku yang lebih baik dalam menentukan jenis makanan untuk keluarga. Makin tinggi pendidikan seseorang makin mudah menerima informasi sehingga makin banyak pula pengetahuan yang dimiliki, sebaliknya pendidikan yang kurang akan menghambat perkembangan sikap seseorang terhadap nilai-nilai atau hal-hal yang diperkenalkan (Notoatmodjo, 2010)

Anak dengan jumlah saudara kandung kurang dari 3 maka akan mendapatkan perhatian yang lebih dari orang tuanya dibandingan dengan anak yang jumlah saudara kandungnya lebih dari 3, sehingga akan berdampak pada pola makan mereka dan pola makan anak menjadi tidak teratur.

Tingkat pendidikan berpengaruh positif dengan perilaku kesehatan. Semakin tinggi pendidikan, maka semakin tinggi pula kesadaran seseorang terhadap tindakan kesehatan begitu pula dengan semakin tinggi pendidikan orang tua semakin tinggi pula pengetahuan yang dimiliki orang tua dalam memberikan pola makan yang baik agar tidak terjadi obesitas pada anaknya. Pengetahuan gizi akan mempengaruhi seseorang dalam memilih jenis dan jumlah makanan yang dikonsumsi. Dengan tingkat pendidikan yang tinggi seharusnya orang tua mempunyai pengetahuan yang cukup tentang jenis makanan yang sehat dan bergizi untuk keluarganya ,sehingga mampu mengarahkan anak untuk membiasakan diri makan makanan yang sehat

\section{Hubungan Pola Makan Dengan TerjadinyaObesitas anak usia} sekolah di SDN 1 Kutorejo Kecamatan Kertosono Kabupaten Nganjuk.

Berdasarkan hasil uji Coefisien Contingency didapatkan $\rho$ value $=0,000$ pada $\alpha=0,05$ karena $\rho$ value $\leq \alpha=0,05$ maka Ha diterima sehingga ada hubungan 
Jenis pola makan dengan terjadinya obesitas anak usia sekolah di SDN 1 Kutorejo Kecamatan Kertosono Kabupaten Nganjuk dengan tingkat hubungan kuat.

Hasil analisis data memperlihatkan terdapat hubungan antara pola makan dengan obesitas pada anak usia sekolah, menurut penelitian yusaac dkk (2007) menunjukkan bahwa subjek penalitian yang mengalami obesitas memiliki pola makan yang tidak seimbang yaitu pola konsumsi lemak dengan frekuensi sering yang proporsinya lebih besar dibandingkan dengan yang tidak obesitas.

WHO juga menyatakan bahwa perubahan global pada pola makan yang cenderung terjadi pada anak obesitas adalah peningkatan masukan makanan padat energi yang merupakan tinggi lemak dan gula namun rendah vitamin, mineral, dan mikomutien sehat lainnya. Hal ini tidak jauh berbeda dengan penelitian Biro dkk (2010) yang menunjukkan bahwa kecenderungan mengkonumsi makanan ringan, makanan siap saji, dan minman dengan pemanis buatan dapat menyebabkan peningkatan berat badan pada anak karena mengandung kalori yang tinggi.

Pola makan yang tidak seimbang atau mengkosumsi kalori yang berlebih daripada mengkonsumsi kalori dengan seimbang akan beresiko terjadinya obesitas anak usia sekolah. Orang tua anak harus ada upaya agar anak tidak mengkonsumsi makan secara berlebihan ,upaya orang tua agar anak makan secarateratus baik frekuensi, jenis makanan maupun jumlah makanan.

\section{KESIMPULAN}

Ada hubungan antara pola makan dengan terjadinya obesitas anak usia sekolah di SDN Kutorejo 1 Kecamatan Kertosono Kabupaten Nganjuk dengan $\rho$ value $=0,000$ pada $\alpha=0,05$ karena $\rho$ value $\leq \alpha=0,05$ maka Ha diterima sehingga ada Hubungan Pola Makan Dengan Terjadinya Obesitas Anak Usia Sekolah Di SDN Kutorejo 1 Kecamatan Kertosono Kabupaten Nganjuk dengan tingkat hubungan kuat. Dalam penelitian ini didapatkan hasil bahwa ada hubungan antara pola makan dengan terjadiya obesitas anak. Pola makan yang kurang baik sangat berpengaruh terhadap terjadinya obesitas, dimana bila anak usia sekolah mendapat pola makan yang tidak seimbang atau mengkosumsi kalori yang berlebih dari pada mengkonsumsi kalori dengan seimbang akan beresiko terjadinya obesitas anak usia sekolah, semoga kedepan penelitian ini dapat dikembangkan lagi, dan dapat lebih berguna bagi dunia kesehatan utamanya keperawatan 


\section{DAFTAR PUSTAKA}

Biro Fm. Wien M. 2010.Childhood Obesity And Adult Morbidities. The American Journal Of Clinical Nutrition.

Budiyati. 2011. Faktor Penyebab Obesitas Pada Anak Usia Sekolah Di SD Islam AL-AZHAR 14 Kota Semarang. http://ib.ui.ac.id/detail?id=20280289\& lokasi=lokal. Diakses pada tanggal 08 Mei 2018 15.00 WIB.

Depkes RI. 2013. Riset Kesehatan Dasar. Jakarta: Depkes RI

Depkes RI 2008. Pedoman Umum Gizi Seimbang.Jakarta: Ditjen Pembinaan Kesehatan Masyarakat. Direktorat Bina Gizi Masyarakat.

Freitag H. 2010. Bebas Obesitas Tanpa Diet Menyiksa. Yogyakarta.Medika Pressindo.

Irwan Hariyanto.2012.Faktor-Faktor Yang Berhubungan Dengan Obesitas Pada Anak Usia Sekolah Dasar Di Jawa Tengah. http://lib.ui.ac.id/file?file=digital/2031411 1-T\%2031190-Faktor-faktorfull\%20text.pdf. Di akses pada tanggal 08 Mei 2018 jam 14.00 WIB.

Notoatmodjo. 2010. Ilmu Perilaku Kesehatan. Jakarta : Rineka Cipta.

Nursalam, 2016. Metodelogi Penelitian Ilmu Keperawatan : pendekatan Praktik Edisi 4. Jakarta : Salemba Medika.

Roviana Nurda. 2017. Hubungan Pola Makan Dan Persepsi Orang Tua Dengan Kejadian Obesitas Pada Anak Usia 8-13 Tahun Di SD Budi Mulia Dua SeturanYogyakarta.http://digilib.unisayog ya.ac.id/2865/1/RovianaNurdaA 1610104 471 8A DIV Naskah Publikasi.pdf Di akses pada tanggal 08 Mei 2018 jam 14.00 WIB

Soetjiningsih, Ranuh Gde IG,N. 2013. Tumbuh Kembang Anak Edisi 2. Jakarta : EGC.
Sulistyoningsih, H. 2011. Gizi untuk kesehatan ibu dan anak. Edisi pertama. Yogyakarta: Graha Ilmu

WHO. 2007. WHO Reference 2007 for Child And Adolescent. WHO, Gevan.

Yussac MMA, Cahyadi A, Dkk. 2007. Prevalensi obesitas pada anak 4-6 tahun dan hubungannya dengan asupan serta pola makan. Majalah Kedokteran Indonesia 